\title{
Erratum to: Role of Src in breast cancer cell migration and invasion in a breast cell/bone-derived cell microenvironment
}

Brant Pohorelic $\cdot$ R. Singh $\cdot$ S. Parkin •

K. Koro - A.-D. Yang • C. Egan - A. Magliocco

Published online: 11 October 2011

(C) Springer Science+Business Media, LLC. 2011

Erratum to: Breast Cancer Res Treat

DOI 10.1007/s10549-011-1753-2

The original publication of the article has been published with incorrect values in table row "Y419/Total Src" pertaining to Fig. 1, part $b$. The correct values are given in the table presented below.

The online version of the original article can be found under doi:10.1007/s10549-011-1753-2.

B. Pohorelic - R. Singh - S. Parkin - K. Koro - A.-D. Yang

C. Egan $(\bowtie) \cdot$ A. Magliocco

Departments of Oncology and Pathology and Laboratory,

Medicine, Faculty of Medicine, University of Calgary,

133129 St, NW, Calgary, AB T2N 4N2, Canada

e-mail: egan@ucalgary.ca 
Fig. 1 Quantitation of total and phospho-Src in a panel of six breast cancer cell lines by Western blot. a Representative relative amounts of total and phospho-Src and actin in breast cancer cell lines. Blots for Src and phospho-Src were each run with their own actin control and the actin control shown is representative. $\mathbf{b}$ Values of total and phospho-Src by

densitometric scan from panel A normalized to actin. Each Src blot was normalized to a different actin loading control, and normalized values can be compared with a across the rows but not down the columns. c Graphic representation of the values for total Src normalized to actin. d Graphic

representation of the values of phospho-Src normalized to total Src a

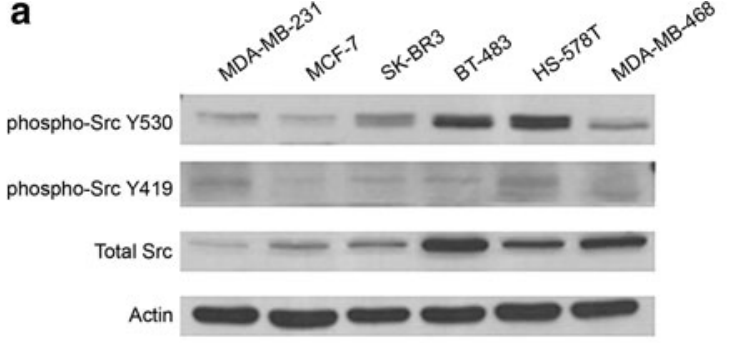

b

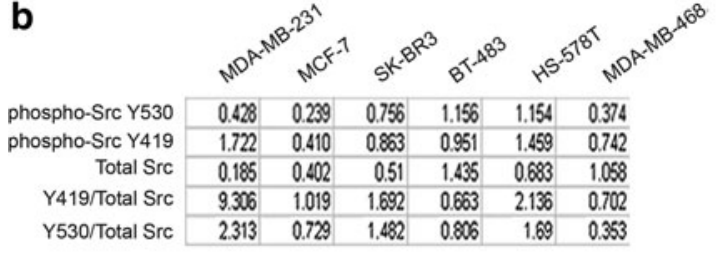

C
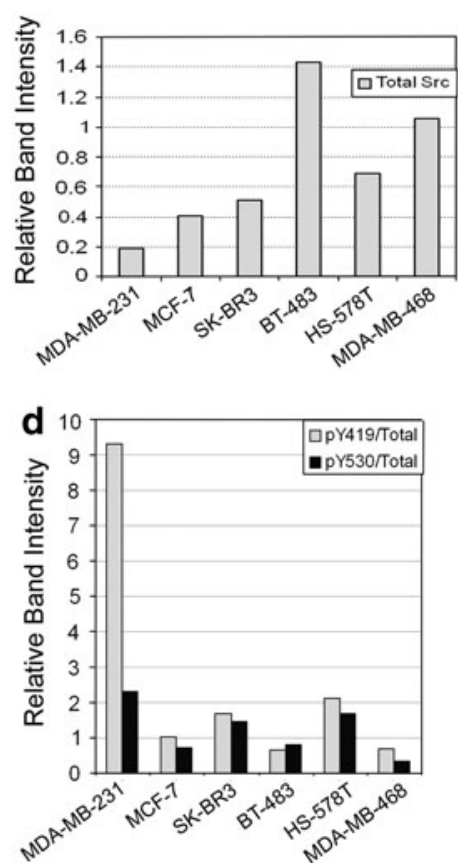